\title{
Object permanence in the African Grey parrot (Psittacus erithacus)
}

\author{
IRENE M. PEPPERBERG and FLORENCE A. KOZAK \\ Northwestern University, Evanston, Illinois
}

\begin{abstract}
An African Grey parrot was assessed for object permanence using tasks designed for human infants. The subject showed concepts of object permanence directly comparable to primate and nonprimate mammalian species similarly tested. Because the subject has also been the focus of a study on interspecies communication, the results are discussed in terms of the possible relationship between sensorimotor intelligence and language-like behaviors.
\end{abstract}

In the Piagetian framework, a basic component of perception and cognition is object-concept: the understanding that there are invariant physical properties attached to objects in the world. Such knowledge seems almost too obvious a part of the human intellect to warrant investigation; however, the process by which a child-or another animal species-develops this notion is poorly understood, and few researchers agree on methods for quantifying this development (e.g., see Bower, 1982; Flavell, 1985; Harris, 1983).

The most commonly discussed aspect of object-concept is object permanence, the realization that an object has a physically distinct identity fixed in time and space. According to Piaget $(1952,1954)$, this concept takes 2 years to develop in a child, and occurs within the period of the six-step sensorimotor stage of intelligence. Although sometimes criticized as too rigid and insensitive to the possibility that environmental stimulation could accelerate cognitive growth (see Bruner, 1964; Steckol \& Leonard, 1981), the Piagetian framework has undeniable usefulness as a yardstick in comparative studies (ChevalierSkolnikoff, 1976): Because the results of cross-species comparative work are often rendered ambiguous by significant variations in experimental design between laboratories (e.g., Bateson, 1979; Kroodsma, 1982), tasks that enable researchers to compare directly the abilities of various species are particularly valuable.

Nonhuman primates tested with object permanence measures include squirrel monkeys (Saimiri sciurea; Vaughter, Smotherman, \& Ordy, 1972), stumptail macaques (Macaca arctoides; Parker, 1977), Japanese macaques (Macaca fuscata; Antinucci, Spinozzi, Visalberghi, \& Volterra, 1982), rhesus monkeys (Macaca mulatta; Wise, Wise, \& Zim-

This research was supported by NSF Grant BNS 84-14483 and the Harry Frank Guggeneheim Foundation. We thank Stephanie Moore, Denise Neapolitan, and Kathryn Spangler for their assistance in performing the experiments, and Roger Fouts, Ariane Etienne, and other reviewers for their thoughtful criticisms. I.M.P. thanks L. Jacobsen of the Primate Library at the University of Wisconsin, Madison, for access to the reference collection. Reprints may be obtained from the first author at the Department of Anthropology and Program on Language and Cognition, Northwestern University, Evanston, IL 60201. mermann, 1974), two New World monkeys (Cebus capucinus and Lagothrica flavicauda; Mathieu, Bouchard, Granger, \& Herscovitch, 1976), lowland gorillas (Gorilla gorilla; Redshaw, 1978), and language-trained and nonlanguage-trained chimpanzees (Pan troglodytes; Hallock \& Worobey, 1984; Mathieu et al., 1976; Wood, Moriarty, Gardner, \& Gardner, 1980). The results have been compared with those of children, and suggest that the concept of object permanence, as described by Piaget $(1952,1954)$, is not specific to humans.

Object permanence has also been demonstrated in nonprimate mammals. Gruber, Girgus, and Banuazizi (1971) found that cats were capable of only the first four stages of object permanence, but Triana and Pasnak (1981), using objects of greater relevance (food items with careful control for odor cues), demonstrated Piagetian Stage 6 sensorimotor intelligence in both dogs and cats.

Few studies have investigated object permanence in Aves, even though natural behaviors such as food caching (e.g., Kamil \& Balda, 1985) and cavity-nesting would make it seem a likely adaptive trait. Etienne (1973) studied object permanence in the young domestic chicken in relation to imprinting problems, and concluded that the chick's capacity (1) did not go beyond a stimulus-response association and (2) was unrelated to any general stage of cognitive development. Avian capacities, however, should not be judged solely on the basis of the domestic chicken. The chicken has relatively little of those neural areas which, in avian species, are thought to mediate behaviors regarded as indicative of intellectual capacity (e.g., Hodos, 1982; Stettner \& Matyniak, 1968; but see Marler, Duffy, \& Pickert, 1986a, 1986b). More likely species for a study of object permanence are sturnids, corvids, and psittacids, which have already demonstrated a significant capacity for $\operatorname{cog}$ nitive achievement (Kamil \& Hunter, 1970; Krushinskii, 1960; Pepperberg, 1983; Zorina, 1982; also Etienne, 1984, personal communication, 1985).

The subject for the present assessment of object permanence was an African Grey parrot that was the focus of a concurrent study on (1) the degree to which an avian subject could acquire functional use of the sounds of English speech, and (2) the extent to which such speech could 
be used to investigate its cognitive capacities. Details of the training methods and results of that study can be found elsewhere (Pepperberg, 1979, 1981, 1983, in press-a, in press-b). This parrot had already learned to label objects, colors, shapes, and numerical quantities, and had demonstrated a limited facility for categorization. Although there is significant debate over the possible correlation between language development and success on object permanence tasks (e.g., Bates, Benigni, Bretherton, Camaioni, \& Volterra, 1979), investigating such a correlation was not the primary focus of the present study. Rather, we initiated this study because informal evidence had suggested that our subject possessed some degree of object concept (e.g., his visual tracking of objects and apparent memory, over time, of favored food items hidden in human fists, in various metal tins, and in overturned cups), yet we knew of no formal assessment of object permanence in psittacids (see, e.g., Lea, 1984).

Following previous studies (e.g., Redshaw, 1978; Wood et al., 1980), we used the Uzgiris and Hunt (1975) scales of infant development of object permanence (see Appendix), including identical numbers of trials and repetitions. Although the value of standardized tasks such as those of Uzgiris and Hunt for assessing object permanence has been questioned (see discussions by Bower, 1982; Flavell, 1985; Harris, 1983), those tasks were employed with only minor modifications so that our data would provide direct cross-species comparisons of level of achievement.

Many of the primate studies focused on cross-species correlation of success on a given scale with age. Because our subject was approximately $81 / 2$ years old at the time of this study, we did not perform a comparison of child, nonhuman primate, and parrot with respect to age-related development. Our interest was in determining whether a psittacid ultimately had the capacity for object permanence. Following the arguments of Uzgiris and Hunt (1975) and Triana and Pasnak (1981), we suggest that his reliable performance at a given level may represent the developmental capacity of the species; in that sense, age is not a factor.

\section{METHOD}

\section{Subject}

The experimental subject was an 81/2-year-old African Grey parrot named Alex, which had been the focus of a study on interspecies communication and cognitive abilities for $71 / 2$ years. He was allowed free access (contingent upon his vocal requests; e.g., "Wanna go gym") to all parts of the laboratory for the 8-h/day that trainers were present; hence, trials occurred at various locations. He was, however, confined to a standard cage $(\sim 62 \times 62 \times 73 \mathrm{~cm})$ during sleeping hours. Water and a standard seed mix for psittacids (sunflower seeds, dried corn, kibble, oats, safflower, etc.) were available continuously; fresh fruits, vegetables, specialty nuts (cashews, almonds, pecans, walnuts) and toys (keys, pieces of wood, paper, rawhide, etc.) were provided at the bird's vocal requests (e.g., "I want cork").

\section{Apparatus}

Experimental manipulations were generally made on a clothcovered metal tray held in front of the subject; this tray was also used to present objects to the subject in a concurrent study on numerical concepts (Pepperberg, in press-b). During trials, the subject sat on his gym (a construction of wooden dowel rods and ropes), a chair back, a trainer's knee, the top of his cage, or on the desk on which his cage was located. Movement between sites was contingent upon his vocal requests. Various plastic and metal measuring cups, toy barrels, boxes, and pieces of paper were used as screens. The parrot's mode of removing a nonrigid screen (grasping a portion of the object with his beak and pulling to the extent his neck could stretch) was not suited to the use of cloth covers. He could, however, easily grasp the edge or handle of a cup or box and flip it off in a single motion. ${ }^{1}$

A variety of small toys (corks, a key chain, wooden beads, hair clips, jacks, etc.) and food items (nuts, popcorn, grapes, etc.) were used, depending upon what item Alex had most recently requested: because attention was a critical factor, we allowed Alex to choose the item that we would employ. We had found that repetition of similar tasks with identical rewards caused our subject to refuse to comply with our requests (see Pepperberg, 1983, in press-b; for similar findings in other species, see Davis, 1984; Moran, Joch, \& Sorenson, 1983; Triana \& Pasnak, 1981; Wise et al., 1974).

Alex's performance did not differ between food and nonfood items, and all tasks were performed at least once with nonfood items. All of the items used as covers could contain food at various times during the day, and the tray was often used to present food items in other experiments occurring simultaneously (Pepperberg, in press-b). Correct responses enabled Alex to eat the food, interact with the toy, or request a different item; in some cases, he refused the food item he had uncovered and requested a nonfood item instead. It is therefore unlikely that odor cues were of any particular importance in trials that employed foods.

\section{Tasks}

The Appendix outlines the experimental tasks in Uzgiris and Hunt's (1975) Scale 1: The Development of Visual Pursuit and the Permanence of Objects. Tasks 1-10 involve visible displacements, in that the subject watches the disappearance of an object. In Tasks 1 and 2 , the ability of the subject to follow the object is examined. In Task 3 , the object is partially covered by a screen; in Task 4 , it is fully covered. In Task 5 , there are two possible hiding places, but the location remains constant for several trials in a row; the question here is can the subject recognize when the location is changed? In Task 6 , the placement of the object alternates on each trial; Task 7 repeats this procedure with three possible hiding places. Task 8 involves successive visible displacements; that is, while the subject watches, the object is hidden in the experimenter's hand and is passed from left to right (or right to left) under each cover, with the experimenter showing the object in her hand between covers, until it is placed under the last cover. Task 9 involves a single placement but multiple overlapping covers; the point here is to determine whether the subject will persist and remove three successive covers to obtain the object.

Tasks 10-13 repeat Tasks 4-7, but involve invisible displacements: the object is first concealed in a small box or in the experimenter's hand, then emptied under a different cover; only then is the subject shown that the original hiding place is empty. Thus, the subject cannot view the transfer, but can only infer that it has occurred. In Task 14, the procedure is the same as in Task 8 , but the subject is not shown that the object remains in the experimenter's hand while it is being transferred between covers. Task 15 involves a "trick," in that the subject is led to believe that it is a repetition of Task 14; however, the experimenter places the object under the 
first cover. The question here is will the subject go to the place where the object logically should be hidden? This is considered the definitive test for Piagetian object permanence (Uzgiris \& Hunt, 1975); but see discussion in Flavell, 1985); it also rules out the subject's use of cues such as odor (see Triana \& Pasnak, 1981).

For each task, Uzgiris and Hunt (1975) provide critical actions that describe the response they consider to be indicative of the subject's comprehension of the task in question (cf. Bower, 1982). The particular response is one (or in a few cases, two) of several mutually exclusive responses to the task. These responses are all general enough to allow for comparison across species.

\section{Procedure}

Trials were conducted by two experimenters working together. One performed the experiments and one acted as observer and recorder. Several different humans were involved, and roles were often interchanged so that the parrot did not become adept at possible cues presented by a single individual. All humans were, however, familiar to the subject.

During a session, Alex was tested with each of the tasks in the sequence, as listed in the Appendix, except that in the first experiment order was varied by eliminating Tasks 5-8 (see below). The observer recorded the behavior of the parrot on the trial sheets as given in the Appendix, or noted any other behavior. Each task was administered until the subject attained the criterion of success described below, which matched that of Wood et al. (1980). When Alex passed the requisite number of trials for one task, trials for the next task began immediately. Note was taken of mistrials, in which the subject interfered with the covers or objects before the displacements could be completed ${ }^{2}$ (see Wood et al., 1980, for similar occurrences with chimpanzees). Sessions lasted until our subject stopped working entirely (e.g., began to ignore us and preen, ask for numerous successive changes of location each time the tray was presented, or request different objects in rapid successionsee Pepperberg, 1983, in press-b). When the subject failed to attend to any part of the trial, the session was ended; it was resumed (1) after a period of free-choice requests, (2) after a break for lunch, or (3) on a succeeding day. All 15 tasks were administered similarly. The study was begun on December 21,1984 , and was completed on January $31,1985$.

Trials, like those reported in Wood et al. (1980), were interspersed with talking and with eating or playing with the objects uncovered during the trials. Similarly, the experimenter often encouraged the subject with vocal requests such as, "Look! Where's the cork?" or "Pay attention! Go find the key chain."

Because the procedure involved face-to-face interaction between the subject and the experimenters, there existed the possibility of cuing by the experimenter's direction of gaze (Gardner \& Gardner, 1975; Wood et al., 1980). The face-to-face procedure is, however, standard for this type of Piagetian testing, and any cuing would occur equally for all subject species. Several reasons have been presented by other researchers (e.g., Triana \& Pasnak, 1981; Wood et al., 1980) for rejecting the influence of such cuing; these will be repeated here briefly. First, the earliest of the tests (the visible displacements) are performed with cues that are far more obvious than eye gaze or the facial expression or body posture of the experimenter; in some situations, the object remains in full view. Second, Triana and Pasnak (1981) report that even obvious pointing to the correct solution will not aid subjects whose cognitive capacities are unequal to the tasks. We note that intentional pointing in one instance on the last trial of a previously correctly performed task did not encourage our subject to perform correctly after he had stopped paying attention during the session. Finally, the results of Task 15, in which the subject chooses the place where the object logically should be, but not where the experimenter knows it is, provides additional support against cuing as a strategy. ${ }^{3}$

\section{Scoring}

A trial was scored as correct if Alex performed one of the critical actions (see Appendix) within 1 or 2 min of the time of hiding. The criterion for success was, as in previous studies, correct performance over three consecutive testing sessions for each task with no more than one incorrect trial in no more than two of the three consecutive sessions. When Alex achieved criterion on a particular task, he was no longer asked to perform that task in subsequent sessions.

\section{RESULTS AND DISCUSSION}

\section{Experiment 1}

Table 1 shows the results of the trials for the object permanence tasks that Alex completed. The tasks in the table are grouped into series following Uzgiris and Hunt (1975) and Wood et al. (1980).

Tasks 1-4. Tasks 1 and 2 measure the ability of the subject to pursue a slowly moving object; Tasks 3 and 4 measure the subject's ability to find objects that are obscured partially or fully by a single cover. Alex responded appropriately on all four tasks in the first session. In the first task, that of tracking a moving object, Alex followed very closely the movement of the yellow wooden bead used as a "lure"; we saw his pupils dilate and contract as he focused. On the third trial of this task, he attempted to grab the bead while it was in motion. In the second task, tracking an object that briefly disappears from view, Alex bent his head in what appeared to be a search for the object (a small orange wooden cylindrical bead) when it was out of view. During the third task, the same bead was partially covered by a small paper towel. On the first trial, Alex removed the towel; on the second, he withdrew the bead. On the third trial, he seemed more interested in the paper towel: he removed it and began to shred it. We therefore changed lures, using a plastic pen for the fourth trial; Alex immediately removed it from under the towel. In the fourth task, a new object, a purple wooden bead, was hidden completely by a bunched

Table 1

Results of Trials for Tasks Involved in Experiment 1

\begin{tabular}{cc}
\hline & Number of Trials \\
\hline Visual Pursuit of Slowly Moving Objects \\
Task 1 & 3 \\
Task 2 & 3 \\
Search for Simply Hidden & Objects \\
Task 3 & $3[1]$ \\
Task 4 & 4 \\
Task 5 & $*$ \\
Search Following More Complex Hidings & 3 \\
Task 9 &
\end{tabular}

Note-Numbers represent the number of times Alex performed the action designated by Uzgiris and Hunt (1975) as critical for comprehension. Numbers in brackets represent the number of additional trials in which Alex interacted with the cover and ignored the uncovered lure. The number of repetitions designated as critical for comprehension is noted in the Appendix. *Alex failed to respond appropriately (see text). 
up paper towel. Alex ignored the materials and climbed to the top of his cage; we paused for a few minutes and restarted. This time Alex pulled at the towel, but his reach, even after two tries, was not great enough to uncover the bead. He banged his beak against the table, which for him is generally a sign of frustration (Pepperberg, unpublished observation). We switched to a different cover-a metal measuring cup with which he was familiar-and hid nuts. On three successive trials, he picked up the cup and uncovered the nuts.

Task 5. This is the first instance in which the subject must choose between two possible hiding places. We placed a red plastic cup and the metal cup in view, and hid nuts under the red one. Alex chose the metal cup on several successive trials. Although he had had a history of manipulating both cups equally well, we surmised that the experience of previously finding nuts under the metal cup might have affected his choice. We therefore ended the session.

We resumed with one trial of Task 4, which Alex immediately passed. We then restarted Task 5 , this time with two plastic cups, one red and one yellow. Alex's first response was to say "Two"; we told him that he was correct, that there were two cups, and asked him to get the nuts. Two trials with the nuts hidden under the yellow cup were unsuccessful; we switched to red and he chose yellow. At this point, we began to suspect that Alex's failures might be due to his inexperience in dealing with a two-choice test involving physical objects. Our protocols had been such that a physical two-choice problem had never before been presented. He was most commonly presented with a single object in conjunction with vocal requests for information about that object; his choice was then one of numerous possible vocalizations in his repertoire, rather than a physical response. Multiple objects had previously been present in his environment in only two situations: either in a box, located near his cage and containing approximately 100 objects, from which he could choose anything during limited "free periods" during the day (Pepperberg, 1981) or in a specific collection of (usually identical) objects for which he was asked to label quantity (Pepperberg, in press-b). In the latter instance, his reward would be the entire collection. To see if his failure on Task 5 could be due to lack of experience rather than a conceptual deficit, we proceeded to Task 9, which was the next task in the series that did not involve a multiple-choice situation.

Task 9. Alex immediately performed the appropriate response of successively removing the three superimposed covers. Because success on more advanced tasks implies understanding of previous ones (Uzgiris \& Hunt, 1975), this result suggested that Alex's Task 5 failure was not a conceptual deficit (see below).

We did, however, want to learn if experience with multiple-choice situations would enable Alex to perform Tasks 5-8 appropriately. Unlike the protocol used in Uz- giris and Hunt's (1966) film, we did not demonstrate where the object was hidden in the two-choice procedure; such a demonstration might actually have served to train our subject on the task and invalidate any subsequent test of this ability (Chevalier-Skolnikoff, personal communication, 1984; Etienne, 1984). Instead, we presented our subject with several multiple-choice opportunities during the course of the next day. These were not trials: he was simply given two cups or two boxes (i.e., covers), each of which had a different object placed under or on it; occasionally, the cup or box was placed on its side, and the object was then placed inside. There was no "correct" choice, but rather a significantly different (although, as best we could design it, equally reinforcing) result based on choice of cover.

We then proceeded to repeat the tasks.

\section{Experiment 2}

The first session began with Task 5, since Tasks 1-4 had been completed in Experiment 1. We then repeated the entire set of tasks twice. The results for the Task 5-15 and Task 1-15 sessions are reported together. Table 2 shows the results of the trials for each of the tasks. As

Table 2

Results of Trials for Tasks Involved in Experiment 2

\begin{tabular}{ccc}
\multicolumn{3}{c}{ Number of Trials } \\
\hline Session 1 & Session 2 & Session 3
\end{tabular}

Visual Pursuit of Slowly Moving Objects

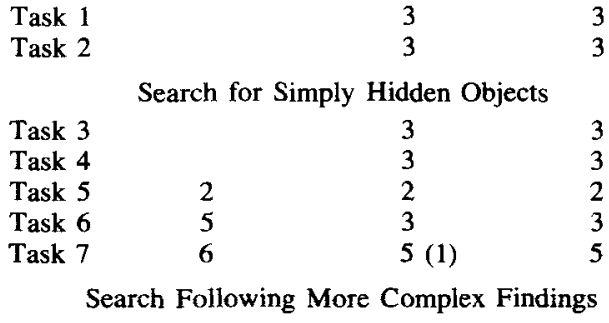

$\begin{array}{llll}\text { Task } 8 & 5 & 3 & 3, \mathrm{c}\end{array}$

Task 9

3

3

Search Following an Invisible Displacement

$\begin{array}{llll}\text { Task } 10 & 3 & 3 & 3 \\ \text { Task } 11 & 2 * & 2 & 2 \\ \text { Task } 12 & 3 & 3, d & 3 \\ \text { Task } 13 & 5(1), b & 5 & 5\end{array}$

Search Following Successive Invisible Displacements

Task $14 \quad 4 \quad 4(2) \quad 4(2)$

$\begin{array}{llll}\text { Task } 15 & 2 & 2 & 2\end{array}$

Note-Numbers represent the number of times Alex performed the action designated by Uzgiris and Hunt (1975) as critical for comprehension; letters designate which of the incorrect actions he performed in addition to the correct responses (see Appendix). Numbers in parentheses represent the additional number of mistrials, in which Alex interfered with the covers before the trial could be completed. The number of correct repetitions designated as critical for comprehension is noted in the Appendix. Tasks $1-4$ and 9 were repeated for only two sessions, they had been correctly performed in Experiment 1. *Alex initially responds by tossing the cups used as covers eight times in a row. We stop for the day and restart the next day. See description in text. 
before, the tasks in Table 2 are grouped into series following Uzgiris and Hunt (1975) and Wood et al. (1980).

Tasks 1-4. Alex again responded immediately and appropritely to all trials of these four tasks. Interestingly, Uzgiris and Hunt (1975) and Wood et al. (1980) found it difficult to elicit these early patterns of behavior once they had demonstrated higher levels of achievement. Alex may have responded because the tasks were still rather novel: he had had little formal experience with such tasks prior to these experiments, although he had shown some evidence of tracking objects that he had tossed, and an ability to uncover objects in an informal situation (see Footnote 1).

Tasks 5-13. Alex responded appropriately on all trials of all tasks. A few interesting points: On a final trial of Task 6, after eating all the nuts under the correct cover, he turned over the incorrect one as well. On another trial of Task 6 , he requested that we "Go pick up cup." On the first set of trials of Task 11-the first invisible displacement to involve two screens-Alex demonstrated a significant preference for the cup placed to his right (eight trials in a row). We were not sure if this meant that he was unable to do the task, or if the tossing of the cups had become its own reward. We ended the sessions for that day; the next day he performed the task immediately and correctly. We found that he often resorted to idiosyncratic choice at the end of a day.

Tasks 14-15. On the first set of trials, Alex responded immediately and correctly on Task 14; on Task 15, he responded immediately by overturning the cover where the object logically should have been hidden. Of particular interest, however, was a clear "'Yip" (occasionally used by our subject when startled) that accompanied his failure to obtain the expected reward. On subsequent trials of Task 14, he occasionally knocked over all covers simultaneously with a single motion of his head, often before the displacement had been completed. Such occurrences, which were listed as mistrials, occurred four times during the trials of the last two sessions.

Alex reached criterion on all tasks within three sessions, the minimum number required by the Uzgiris and Hunt protocols.

\section{GENERAL DISCUSSION}

Although previous studies had demonstrated behaviors related to object permanence in corvids (European jay, Garrulus glandarius: Bossema, 1968, 1979; Clark's nutcracker, Nucifraga columbiana: Kamil \& Balda, 1985; Vander Wall \& Balda, 1977, 1981; crows: Krushinskii, 1960; Zorina, 1982), no detailed study had been undertaken with psittacids-birds that are thought to be of comparable intelligence. Our study demonstrates that at least one individual psittacid, an African Grey parrot, exhibits a degree of object permanence comparable to that of mammals and primates similarly tested. Furthermore, our results may have several interesting implications.
First, our findings in Experiment 1-Alex's initial noncomprehension of the midrange tasks, 5-8, with simultaneous comprehension of Task 9-suggest that development of competence on particular tasks related to object permanence can be a consequence of environmental influences, as well as conceptual abilities (see Etienne, 1984). According to the standard methodology (Uzgiris \& Hunt, 1975), the study should have concluded with Alex's initial failure on Task 5 . Only our suspicion that his failure was due solely to lack of experience with a particular type of object manipulation (see, e.g., Bruner, 1964; Etienne, 1973; Held, 1965; Landers, 1968) led us to attempt Task 9, which was beyond his apparent level of ability. And, because success on advanced tasks implies comprehension of cognitive abilities underlying the earlier tasks (Uzgiris \& Hunt, 1975), a second attempt at Tasks 5-8 was then feasible. Although it is possible that our findings were attributable to a real difference in the sequence of task achievement in mammals versus nonmammals, we argue that our results were more likely due to a specific, if unintentional, human-engineered deficit, particularly because of the speed with which it was remedied. The ability to achieve sensorimotor coordination depends on the opportunity to correlate experience in some instance and to generalize it across situations (e.g., Etienne, 1973, 1984; Held, 1965); total lack of such experience would be expected to affect a particular performance adversely, without affecting overall cognitive abiilty (see, for a more general case, Rubinstein, 1979).

Second, although the present study indicates that a nonprimate, nonmammalian subject is capable of the inference subsumed by Piagetian object permanence problems, it is important to realize that similar levels of correct responding do not necessarily reflect the operation of the same cognitive mechanisms. That is, the complexity of the problem-solving strategies underlying the same level of performance may be different in different species (Antinucci et al., 1982; Harris, 1983). Alex's type of representation of the object may be qualitatively different from that of a young child or chimpanzee; for example, Alex may not remember what was hidden, but only that the object was something of interest. Thus, the demonstration of parallels can only suggest, but not prove, similarities between the underlying mechanisms.

Third, the argument can be made that Alex's abilities are unique in that his detailed training on tasks such as labeling and categorization has facilitated comprehension of tasks of object permanence. Although Rice (1980) does not believe that linguistic input can teach a nonlinguistic concept for which a subject is unready, some researchers (e.g., Premack, 1983, 1984) have suggested that the abilities of animals trained with language-related tasks significantly differ from those without such training. Repetition of this particular set of experiments with an untrained parrot would therefore be of considerable interest. Note, however, that work by Chardard-Segurel $(1984,1985)$ suggests that comprehension of a human lan- 
guage is not a prerequisite for some of the (more advanced) Piagetian sorting tasks of the preoperational period: her Grey parrots successfully completed such tasks, which supposedly presuppose abilities such as object permanence (Piaget, 1952, 1954). In a discussion of more advanced skills, Hall et al. (1980) proposed, on the basis of their research with chimpanzees and normal and retarded children, that language and language-type skills may facilitate performance on such Piagetian sorting tasks by aiding the subject to use conceptual, rather than perceptual, cues. This is also true in a sense for the simpler task of object permanence, in that recalling the existence of a hidden object is a conceptual, rather than a perceptual, task. But it is this shift from perceptual to conceptual strategies that may be the crucial step in the development of real object permanence: the latter strategy implies that the subjects' experience has been absorbed as a basic cognitive strategy that can be generalized across situations (see Etienne, 1973, 1984).

Other researchers (e.g., Ginsberg \& Opper, 1969; Steckol \& Leonard, 1981) suggest that the presence of cognitive mechanisms of the type found during the sensorimotor, preoperational, and concrete operational periods (the latter two being more advanced stages than those discussed here) facilitate use of language by enabling children to represent reality abstractly. Still other researchers suggest the separation of language and thought (e.g., Steklis \& Raleigh, 1979), and others (e.g., Bates et al., 1979) suggest that the appearance of object permanence, while not necessarily related to initial human language abilities (e.g., most holophrasic communication), may be related both to the vocabulary burst that usually occurs late in the second year and to what Hockett (1960) calls "displacement": the ability to refer to and converse about an object not immediately present in space or tine. Lieberman (1984), for example, states that displacement is not present in the communication of very young children, but rather is an aspect that appears subsequent to the two-word stage, after most children achieve object permanence.

Whatever the possible interactions between training on certain concepts and the development of sensorimotor intelligence, our results do demonstrate the capacity of an African Grey parrot with respect to tasks involving Piagetian object permanence. Even if our subject is regarded as "special," his achievements demonstrate that such abilities are within the capacity of a nonprimate, nonmammalian species.

Finally, although there is significant debate on the validity of Piagetian theory for describing the most advanced stages of cognitive development (see Ault, 1983; Flavell, 1985), many tasks used for research into matters such as multiple classifications have been based on the ideas of Piaget, and have thus provided significant data for crossspecies analysis (e.g., Braggio, Hall, Buchanan, \& Nadler, 1982; Chardard-Segurel, 1984; Hall et al., 1980;
Hayes \& Nissen, 1956/1971; for comparisons on other tasks, see Chevalier-Skolnikoff, 1976, 1981). Piagetian studies, whatever their task-related limitations (e.g., Bower, 1982), provide a means for determining similarities and differences in capacities across species by providing a scale against which to test various subjects in exactly the same manner. Such studies may also enable scientists to investigate more fully both the strategies and the mechanisms underlying the strategies for solving such tasks. It has become increasingly apparent that certain cognitive tasks, such as some forms of categorization and labeling of quantity, are within the capacity of even nonprimate, nonmammalian subjects (Pepperberg, 1983, in press-a, in press-b); further work on comparative tasks will aid in better defining the limits of such capacities, and use of the remaining scales of Uzgiris and Hunt (1975) could provide additional means for comparing cognitive capacities across species.

\section{REFERENCES}

Antinucci, F., Spinozzi, R., Visalberghi, E., \& Volterra, V. (1982). Cognitive development in a Japanese macaque (Macaca fuscata). Istituto Superiore di Sanità. Annali., 2, 177-184.

Ault, R. L. (1983). Children's cognitive development. New York: Oxford University Press.

Bates, E., Benigni, L., Bretherton, I., Camaioni, L., \& Volterra, V. (1979). The emergence of symbols: Cognition and communication in infancy. New York: Academic Press.

BAtESON, P. (1979). How do sensitive periods arise and what are they for? Animal Behaviour, 27, 470-486.

Bossema, I. (1968). Recovery of acorns in the European jay. Koninklijke Nederlandse Akademie Van Wetenschappen. Proceedings Series $C, 71,1-5$.

Bossema, I. (1979). Jays and oaks: An eco-ethological study of a symbiosis. Behaviour, 70, 1-17.

Bower, T. G. R. (1982). Development in infancy. San Francisco: W. H. Freeman.

Braggio, J. T., Hall, A. D., Buchanan, J. P., \& Nadler, R. D. (1982). Logical and illogical errors made by apes and children on a cognitive task. Journal of Human Evolution, 11, 159-169.

BRUNER, J. S. (1964). The course of cognitive development. American Psychologist, 19, 1-16.

Chardard-Segurel, C. (1984). Possibilités d'abstraction de différentes qualités sensibles chez le perroquet gris (Psittacus erithacus) en référence à l'enfant humain. Doctoral dissertation, University of the Sorbonne, Paris.

Chardard-Segurel, C. (1985). Cognitive capacities of the African Grey parrot (Psittacus erithacus) on classification problems. Manuscript submitted for publication.

Chavalier-SkolnikofF, S. (1976). The ontogeny of primate intelligence and its implications for communicative potential: A preliminary report. Annals of the New York Academy of Sciences, 280, 173-211.

Chevalier-Skolnikoff, S. (1981). The Clever Hans phenomenon, cuing and ape signing: $A$ Piagetian analysis of methods for instructing animals. Annals of the New York Academy of Sciences, 364, 60-93.

Davis, H. (1984). Discrimination of the number three by a raccoon (Procyon lotor). Animal Learning \& Behavior, 12, 409-413.

ETIENNE, A. S. (1973). Developmental stages and cognitive structures as determinants of what is learned. In R. A. Hinde \& J. Stevenson (Eds.), Constraints on learning. New York: Academic Press.

Etienne, A. S. (1984). The meaning of object permanence at different zoological levels. Human Development, 27, 309-320. 
FlAVELL, J. H. (1985). Cognitive development. Englewood Cliffs, NJ: Prentice-Hall.

GaRDNER, B. T., \& GARDNER, R. A. (1975). Evidence for sentence constituents in early utterances of child and chimpanzee. Journal of Experimental Psychology: General. 104, 244-267.

Ginsburg, H., \& OPPER, S. (1969). Piaget's theory of intellectual development: An introduction. Englewood Cliffs, NJ: Prentice-Hall.

Gruber, H. E., Girgus, J. S. , \& Banuazizi, A. (1971). The development of object permanence in the cat. Developmental Psychology, 4, 9-15.

Hall, A. D., Braggio, J. T., Buchanan, J. P., Nadler, R. D., KaRAN, D., \& SAMS, J. B. (1980). Multiple classification performance of juvenile chimpanzees, normal children, and retarded children. International Journal of Primatology, 1, 345-359.

HALlOCK, M. B., W WOROBEY, J. (1984). Cognitive development in chimpanzee infants (Pan troglodytes). Journal of Human Evolution, 13, 441-447.

HARRIS, P. L. (1983). Infant cognition. In M. M. Haith \& J. J. Campos (Eds.), Handbook of child psychology: Infancy and developmental psychobiology (Vol. 2). New York: Wiley.

HAYES, K. J., \& Nissen, C. H. (1971). Higher mental functions of a home-raised chimpanzee. In A. Schrier \& F. Stollnitz (Eds.), Behavior of nonhuman primates (Vol. 4). New York: Academic Press. (Original work published 1956)

Held, R. (1965). Plasticity in sensory-motor systems. Scientific American, 213, 84-94.

Herman, L., Richards, D. G., \& Wolz, J. P. (1984). Comprehension of sentences by bottlenosed dolphins. Cognition, 16, 129-219.

HoCkETT, C. (1960). Logical considerations in the study of animal communication. In W. E. Lanyon \& W. N. Tavolga (Eds.), Animal sounds and communication. Washington, DC: American Institute of Biolog ical Science.

HoDos, W. (1982). Some perspectives on the evolution of intelligence and the brain. In D. R. Griffin (Ed.), Animal mind-human mind. Berlin: Springer.

KAMIL, A. C., \& BALDA, R. P. (1985). Cache recovery and spatial memory in Clark's nutcrackers (Nucifraga columbiana). Journal of Experimental Psychology: Animal Behavior Processes, 11, 95-111.

Kamil, A. C., \& Hunter, M. W., III. (1970). Performance on object discrimination learning set by the Greater Hill mynah, Gracula religiosa. Journal of Comparative \& Physiological Psychology, 13, 68-73.

Kroodsma, D. E. (1982). Learning and the ontogeny of sound signals in birds. In D. E. Kroodsma \& E. H. Miller (Eds.), Acoustic communication in birds: Vol. 2. Song learning and its consequences. New York: Academic Press.

KRUShINSKI, L. V. (1960). Animal behavior: Its normal and abnormal development. New York: Consultants Bureau.

LANDERS, W. F. (1968). The effects of different amounts and types of experience on infant object concepts. Doctoral dissertation, University of Houston. (University Microfilms No. 69-775)

LEA, S. E. G. (1984). Complex general process learning in nonmammalian vertebrates. In P. Marler \& H. S. Terrace (Eds.), The biology of learning. Berlin: Springer.

Lieberman, P. (1984). The biology and evolution of language. Cambridge, MA: Harvard University Press.

Marler, P., Duffy, A., \& PICKert, R. (1986a). Vocal communication in the domestic chicken. I. Does a sender communicate information about the quality of a food referent to a receiver? Animal Behaviour, 43, 188-193.

Marler, P., Duffy, A., \& Pickert, R. (1986b). Vocal communication in the domestic chicken. II. Is a sender sensitive to the presence and nature of a receiver? Animal Behaviour, 34, 194-198.

Mathieu, M., Bouchard, M-A., Granger, L., \& Herscovitch, J. (1976). Piagetian object-permanence in Cebus capucinus, Lagothrica flavicauda, and Pan troglodytes. Animal Behaviour, 24, 585-588.

Moran, G., Joch, E., \& SoRENSON, L. (1983, June). The response of meerkats (Suricata suricatta) to changes in olfactory cues on established scent posts. Paper presented at the annual meeting of the Animal Behavior Society, Lewisburg, PA.

PARKer, S. T. (1977). Piaget's sensorimotor series in an infant macaque: A model for comparing unstereotyped behavior and intelligence in human and nonhuman primates. In S. Chevalier-Skolnikoff \& F. E. Poirier (Eds.), Primate biosocial development. New York: Garland. Pepperberg, I. M. (1979, June). Functional word use in an African Grey parrot. Paper presented at the annual meeting of the Animal Behavior Society, New Orleans.

PePperberG, I. M. (1981). Functional vocalizations by an African Grey parrot (Psittacus erithacus). Zeitschrift für Tierpsychologie, 55, 139-160

Pepperberg, I. M. (1983). Cognition in the African Grey parrot: Preliminary evidence for auditory/vocal comprehension of the class concept. Animal Learning \& Behavior, 11, 179-185.

PePPerberg, I. M. (1986, June). Categorization and second-order concepts in the African Grey parrot. Paper presented at the annual meeting of the Animal Behavior Society, Tucson, AZ.

Pepperberg, I. M. (in press-a). Interspecies communication: A tool for assessing conceptual abilities in the African Grey parrot (Psittacus erithacus). In G. Greenberg \& E. Tobach (Eds.), Language, cognition, consciousness: Integrative levels. Hillsdale, NJ: Erlbaum.

PEPPERBERG, I. M. (in press-b). Evidence for conceptual quantitative abilities in the African Grey parrot: Labeling of cardinal sets. Ethology.

PIAGET, J. (1952). The origins of intelligence in children (M. Cook, Trans.). New York: International Universities Press.

PiageT, J. (1954). The construction of reality in the child. (M. Cook, Trans.). New York: Basic Books.

Premack, D. (1983). The codes of man and beasts. The Behavioral \& Brain Sciences, 6, 125-167.

Premack, D. (1984). Upgrading a mind. In T. G. Bever, J. M. Carroll, \& L. A. Miller (Eds.), Talking minds. Cambridge, MA: MIT Press.

ReDSHAW, M. (1978). Cognitive development in human and gorilla in fants. Journal of Human Evolution, 7, 133-141.

RICE, M. (1980). Cognition to language. Baltimore: University Park Press.

RUBinstern, R. A. (1979). The cognitive consequences of bilingual education in northern Belize. American Ethnologist, 6 583-601.

Schusterman, R., \& KrIEgER, K. (1984). California sea lions are capable of semantic comprehension. Psychological Record, 34, 3-23.

STECKOL, K. F., \& LEONARD, L. B. (1981). Sensorimotor development and the use of prelinguistic performatives. Journal of Speech \& Hearing Research, 24, 262-268.

Steklis, H. D., \& Raleigh, M. H. (1979). Requisites for language: Interspecific and evolutionary aspects. In $H$. D. Steklis \& $M$. H. Raleigh (Eds.), Neurobiology of social communication in primates. New York: Academic Press.

Stettner, L. J., \& Matyniak, K. (1968). The brain of birds. Scientific American, 218, 64-76.

Triana, E., \& Pasnak, R. (1981). Object permanence in cats and dogs. Animal Learning \& Behavior, 9, 135-139.

UZGIRIS, I. C., \& HUNT, J. MCV. (1966). Ordinal scales of infant development, No.1-Object permanence [Film]. Champaign: University of Illinois Films.

UzGIRIs, I. C., \& HuNT, J. McV. (1975). Assessment in infancy: Ordinal scales of psychological development. Champaign-Urbana: Universiy of Illinois Press.

VANDER Wall, S. B., \& BALDA, R. P. (1977). Coadaptations of the Clark's nutcracker and the pinyon pine for efficient seed harvest and dispersal. Ecological Monographs, 47, 89-111.

VANDER WAlL, S. B., \& BALDA, R. P. (1981). Ecology and evolution of food-storage behavior in conifer-seed-caching corvids. Zeitschrift für Tierpsychologie, 56, 217-242.

Vaughter, R. M., Smotherman, W., \& Ordy, J. M. (1972). Development of object permanence in the infant squirrel monkey. De velopmental Psychology, 7, 34-38.

Wise, K. L., Wise, L. A., \& Zimmermann, R. R. (1974). Piagetian object permanence in the infant rhesus monkey. Developmental Psy chology, 10, 429-437.

Wood, S., Moriarty, K. M., Gardner, B. T., \& Gardner, R. A. (1980). Object permanence in child and chimpanzee. Animal Learning \& Behavior, 8, 3-9.

ZorinA, Z. A. (1982). Reasoning ability and adaptivity of behavior in birds. In V. J. A. Novák \& J. Mlikovský (Eds.), Evolution and environment. Praha: C̆SÁV. 


\section{NOTES}

1. This was a learned behavior. The decision to perform the present study began with a probe: in a visible displacement, we hid a nut under a large metal cup that was placed on the desk. Alex walked over, tried to lift the cup, and failed. He then walked to the edge of the desk, looked at the principal trainer (I.M.P.), and said, "Go pick up cup," a novel vocalization. (He had previously produced other vocalizations of the type "Go pick up X," but X had never before been "cup.") The trainer complied with his request and he promptly went over to the nut and ate it. When we tried to replicate this pattern of behavior, he managed to overturn the cup himself after two tries.

2 . We did not often encounter mistrials until we began repetitions of the earlier tasks after having run Task 15: Alex then began to knock all the covers off with a single swipe of his head, occasionally before the final displacements were completed.

3. Because face or body posture could be as much of a cue as eye gaze, we did not believe that use of goggles (e.g., see Schusterman \& Krieger, 1984; Herman, Richards, \& Wolz, 1984) would be of any particular help. Only the complete absence of social interaction would suffice to prevent cuing of this nature, and only studies such as Wise et al.'s (1974) have proceeded in this manner via WGTA testing.

\section{APPENDIX}

Scale I: The Development of Visual Pursuit and the Permanence of Objects, from Uzgiris and Hunt (1975) and Wood et al. (1980)

$\bar{A}$. Visual pursuit of slowly moving objects

1. Follows a slowly moving object through a 180-deg arc (3-4)
a. Does not follow object
b. Follows jerkily through part of arc
c. Follows smoothly through part of arc
d. * Follows object smoothly through complete arc

2. Noticing the disappearance of a slowly moving object (3-4)

a. Does not follow to point of disappearance

b. Loses interest as soon as object disappears

c. * Lingers with a glance on point of disappearance

d.* Returns glance to starting point after several presentations

e. Searches around point of disappearance

B. Search for simply hidden objects

3. Finding an object which is partially covered (3)
a. Loses interest
b. Reacts to the loss, but does not obtain object
c. ${ }^{*}$ Obtains the object

4. Finding an object which is completely covered (3)
a. Loses interest
b. Reacts to loss, but does not obtain object
c. Pulls screen, but not enough to obtain object
d. * Pulls screen off and obtains object

5. Finding an object completely covered in two places (2)

a. Loses interest

b. Searches for object where it was previously found (with respect to location)

c.* Searches for object where it is last hidden
6. Finding an object completely covered in two places alternately (3-5)
a. Becomes perplexed and loses interest
b. Searches haphazardly under one or both screens
c.* Searches correctly under each of the screens

7. Finding an object completely covered in three places (5-7)
a. Loses interest
b. Searches haphazardly under some or all screens
c.* Searches directly under the correct screen

C. Search following more complex hidings

8. Finding an object after successive visible displacements (3-5)

a. Does not follow successive hidings

b. Searches only under the first screen

c. Searches under screen where object was previously found

d. Searches haphazardly under all screens

e. Searches in order of hiding

f. * Searches directly under the last screen in path

9. Finding an object under three superimposed screens (2-3)
a. Loses interest
b. Lifts one or two screens, but fails to find object
c. Removes all screens and obtains object

D. Search following an invisible displacement

10. Finding an object following one invisible displacement (3)
a. Loses interest
b. Reacts to loss, does not search
c. Searches only in the box
d.* Checks the box and searches under the screen
e. ${ }^{*}$ Searches under the screen directly

11. Finding an object following one invisible displacement with two screens (2)

a. Searches only in the box

b. Searches under screen where object was previously found

c. * Searches directly under correct screen

12. Finding an object following one invisible displacement with two screens alternated (3)
a. Loses interest
b. Searches haphazardly under all screens
c. * Searches directly under correct screen
d. Other-searches under screen where last found

13. Finding an object following one invisible displacement with three screens (5-7)
a. Loses interest
b. Searches haphazardly under all screens
c. * Searches directly under correct screen

E. Search following successive invisible displacements

14. Finding an object following a series of invisible displacements (4-6) 
a. Searches only in E's hand

b. Searches only under first one or two screens in the path

c.* Searches under all screens in the path in the order of hiding

d. * Searches directly under the last screen in the path

15. Finding an object following a series of invisible displacements with evidence of representation (2)

a. Searches only under last screen b. Searches haphazardly under all screens

c. * Searches systematically from the last screen back to the first

Note-The number in parentheses following each task description indicates the number of repetitions of the task recommended by Uzgiris and Hunt. An asterisk indicates the action that must be performed for achievement of a step of the scale.

(Manuscript received August 13, 1985; revision accepted for publication June 2,1986 .) 